\title{
The environmental-data automated track annotation (Env-DATA) system: linking animal tracks with environmental data
}

\author{
Somayeh Dodge ${ }^{1 *}$, Gil Bohrer ${ }^{1 *}$, Rolf Weinzierl ${ }^{2}$, Sarah C Davidson ${ }^{1,2}$, Roland Kays $^{3}$, David Douglas ${ }^{4}$,
} Sebastian $\mathrm{Cruz}^{2}$, Jiawei Han ${ }^{5}$, David Brandes ${ }^{6}$ and Martin Wikelski ${ }^{2,7}$

\begin{abstract}
Background: The movement of animals is strongly influenced by external factors in their surrounding environment such as weather, habitat types, and human land use. With advances in positioning and sensor technologies, it is now possible to capture animal locations at high spatial and temporal granularities. Likewise, scientists have an increasing access to large volumes of environmental data. Environmental data are heterogeneous in source and format, and are usually obtained at different spatiotemporal scales than movement data. Indeed, there remain scientific and technical challenges in developing linkages between the growing collections of animal movement data and the large repositories of heterogeneous remote sensing observations, as well as in the developments of new statistical and computational methods for the analysis of movement in its environmental context. These challenges include retrieval, indexing, efficient storage, data integration, and analytical techniques.
\end{abstract}

Results: This paper contributes to movement ecology research by presenting a new publicly available system, Environmental-Data Automated Track Annotation (Env-DATA), that automates annotation of movement trajectories with ambient atmospheric observations and underlying landscape information. Env-DATA provides a free and easy-to-use platform that eliminates technical difficulties of the annotation processes and relieves end users of a ton of tedious and time-consuming tasks associated with annotation, including data acquisition, data transformation and integration, resampling, and interpolation. The system is illustrated with a case study of Galapagos Albatross (Phoebastria irrorata) tracks and their relationship to wind, ocean productivity and chlorophyll concentration. Our case study illustrates why adult albatrosses make long-range trips to preferred, productive areas and how wind assistance facilitates their return flights while their outbound flights are hampered by head winds.

Conclusions: The new Env-DATA system enhances Movebank, an open portal of animal tracking data, by automating access to environmental variables from global remote sensing, weather, and ecosystem products from open web resources. The system provides several interpolation methods from the native grid resolution and structure to a global regular grid linked with the movement tracks in space and time. The aim is to facilitate new understanding and predictive capabilities of spatiotemporal patterns of animal movement in response to dynamic and changing environments from local to global scales.

Keywords: Animal movement, Migration, Movebank, Movement ecology, Remote sensing, Track annotation, Weather

\footnotetext{
*Correspondence: dodge.66@osu.edu; bohrer.17@osu.edu

${ }^{1}$ Department of Civil, Environmental \& Geodetic Engineering, The Ohio State

University, 475 Hitchcock Hall, 2070 Neil Avenue, Columbus, USA

Full list of author information is available at the end of the article
}

\section{Biomed Central}

(c) 2013 Dodge et al.; licensee BioMed Central Ltd. This is an Open Access article distributed under the terms of the Creative Commons Attribution License (http://creativecommons.org/licenses/by/2.0), which permits unrestricted use, distribution, and reproduction in any medium, provided the original work is properly cited. 


\section{Background}

The movement of an organism is influenced not only by its internal state and biological factors driving its movement, but also external factors-the environment and underlying context [1]. Environmental conditions may trigger certain movement patterns or invoke a particular behavioral response, and thus determine local movements or long-distance migrations [2-4]. Animals can optimize their energy expenditure during movement by selecting for locations and times when the conditions are supportive for movement. For example, raptors in their southward fall migration select a preferential mode of uplift that best fits their flight capacity [5-7]. Spatial and temporal variability in environmental conditions may affect all types of movement and any scale, from local to global. Some of the most challenging movements to study include large-scale movement, such as migrations and movements that cross broad geographic areas and traverse diverse environments and landscapes. The added challenge in these studies is that environmental conditions cannot be measured locally as part of the study, because they are needed over a very extensive area. Long-distance migrants include some of our most endangered species, and thus it is critical to address questions at the core of movement ecology, such as "when do animals start migrating?", "which strategies should animals adopt while migrating?" and "do movement rules change in a changing environment, and if so, how?" [8].

Today, with the rapid improvement and miniaturization of tracking technology, movement ecology has entered a new data-rich era, with tremendous growth in animal tracking data at previously unseen spatial and temporal resolution. Complementing this are large arrays of online remote sensing datasets describing the earth system and informing models that forecast the future environment. Combining these datasets is an active area of research, addressing a variety of questions to gain a better understanding of the interaction between animal movement and the environment. Manual annotation of animal tracking data (i.e. adding information to locations by an expert) and simulations of the environment along movement tracks have been successfully used to discover meaningful interactions between movement and external variables $[2,5,7,9-25]$. Improving access to these environmental data will increase our understanding of their broad effects on our planet, motiving the development of RNCEP, a data organization and visualization package for $\mathrm{R}$ for working with data from National Centers for Environmental Prediction (NCEP) / National Center for Atmospheric Research (NCAR) Reanalysis data [26].

Manual annotation is not practical for large global environmental datasets owing to several technical and logistical challenges. The remote sensing datasets needed to study how environmental conditions influence animal movements are provided using complex tiling system in space and time that need to be aggregated to cover the entire movement track. Environmental and animal movement data are usually collected in different spatial and temporal scales and it is therefore necessary to choose appropriate scales for the annotation process. Likewise, an appropriate interpolation technique must be applied in order to integrate data at different resolutions. Moreover, environmental data are diverse in source, format, and projection system. It is essential to apply appropriate data transformation techniques in order to integrate such heterogeneous datasets. Accordingly, effective storage, indexing, and retrieval strategies must be applied to handle large volume of environmental datasets. These challenges limit many potential nontechnical users from accessing these data and applying annotation in a manual mode. Nonetheless, compiling combined movement-environment datasets would be highly beneficial for movement studies. Such vast datasets are well suited for sophisticated, context-aware data mining and pattern recognition techniques that allow researchers to discover patterns of movement in response to changes in the environment $[27,28]$. Hence, an integrated system capable of managing and analyzing movement tracks of animals linked to large remote sensing, climatic, and land use datasets will greatly facilitate the next generation of research into movement ecology.

This paper contributes to movement ecology research by describing a new open system, Environmental-Data Automated Track Annotation (Env-DATA), that automates annotation of movement trajectories with ambient atmospheric observations and underlying landscape information. The aim of the system is to provide efficient movement track annotation and knowledge discovery methods to allow scientists to examine relationships between observed animal movements and a breadth of information about environmental conditions. The Env$D A T A$ system utilizes large computational servers to coregister the animal tracks with environmental data without requiring the user be an expert in the processing of such data. The system facilitates the investigation of biological research questions about movement behavior of animals, including threatened and endangered species that are of concern due to the impact of climate and environmental changes. Env-DATA will facilitate discovery of unique information about niche selection and habitat, movement patterns and landscape connectivity of moving animals, and how these may be affected by variability and long-term changes in climate and landscape. Such knowledge is crucial for planning and management of protected areas and for forecasting population status and habitat needs in future conditions of climate and land use changes. 


\section{Methods}

\section{The movebank Env-DATA system}

This paper primarily focuses on the architecture and technical characteristics of the Env-DATA Track Annotation service. The Env-DATA system expands the capabilities of Movebank, an animal movement data portal (www.movebank.org). Movebank is a free, online database of animal tracking data, which provides biologists and animal movement researchers with a secure online archive to store, manage, process, and share animal movement data [29,30]. Figure 1 illustrates the main components of the Movebank Env-DATA system. The Env-DATA system extensions within Movebank include three main services: (1) the Track Annotation Service, (2) the Track Simulation Service, and (3) the Knowledge Discovery and Visualization Service.

The Track Simulation and the Knowledge Discovery and Visualization services are developed as external libraries using the Java ${ }^{(\mathrm{TM})}$ Platform and the $\mathrm{R}$ programming language. These libraries can read tracking data directly from Movebank (provided the authenticated user has the necessary access rights), and read-write annotated data that were prepared by the Track Annotation Service. They were developed to serve as a convenient access layer to Env-DATA and can be used to transfer data to any other programming or data analysis environment. They can, for example, directly communicate and exchange data with common analysis, visualization and simulation tools like R, MATLAB and Google Earth, and niche analysis software such as Maxent [31]. Examples for such applications using $\mathrm{R}$ and Google Earth are described in the case study section below. In addition, several open movement analysis packages providing tools for knowledge discovery, data mining, modeling, and visualization have been developed by others, including the Move R-package [32] - a movement track analysis and visualization package- and
MoveMine [33] - a track segmentation and classification package.

To ensure its relevance and effectiveness, Movebank services and the Env-DATA system were designed and tested in collaboration with several wildlife research partners from the U.S. Fish and Wildlife Service (FWS), the U.S. National Park Service (NPS), and the U.S. Geological Survey (USGS), who contributed to the design of Env-DATA to ensure its applicability and relevance to contemporary conservation and wildlife management [34-36].

\section{System infrastructure}

The system runs on a Linux application cluster and manages data flow using a MySQL database. Two technically identical installations of the Env-DATA application cluster are located at the Computing Center Garching (RZG) of the Max Planck Society in Garching, Germany, and at the Ohio Supercomputer Center (OSC) of The Ohio State University in Columbus (OH, USA). They serve as storage and processing systems for the environmental data cached directly from their original data sources. Each cluster (i.e. at RZG and OSC) serves different sets of environmental variables depending on their proximity to the original data source. The Movebank application server, which serves the animal tracking data, is also located at the RZG (Figures 1 and 2).

\section{Environmental data}

Our goal is to provide access to the most relevant global gridded datasets of environmental data. Datasets that are available in this first release of Env-DATA include NASA's MODIS vegetation, ocean, ice and fire data products; NCEP Global and North American Regional Reanalyses (NARR); the European Centre for Medium-Range Weather Forecasts (ECMWF) moderate resolution reanalysis; Oregon State University Ocean Net Primary Productivity (NPP); NOAA's Ocean

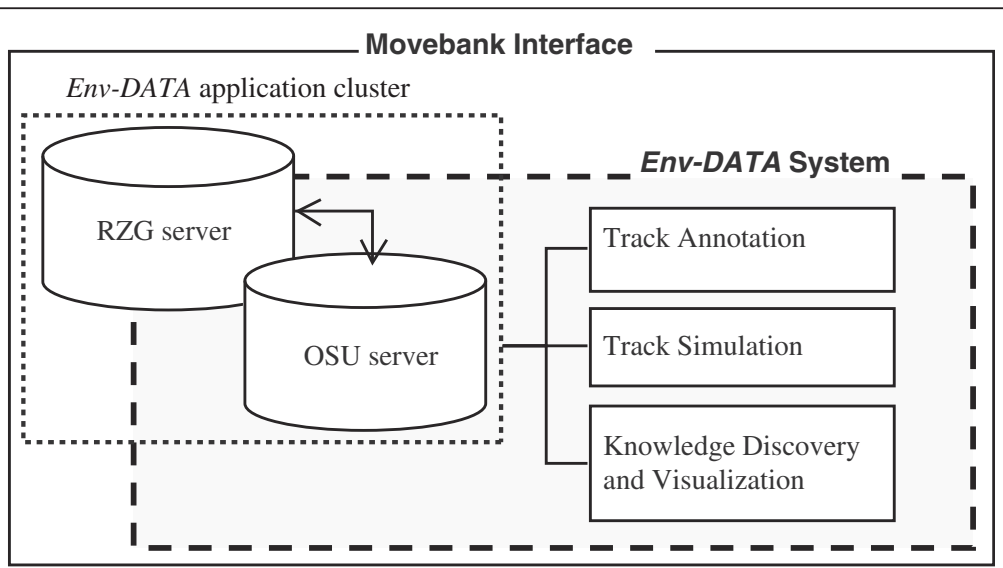

Figure 1 Movebank Env-DATA System. RZG: Computing Center Garching, Germany; OSU: The Ohio State University Supercomputer Center. The gray box highlights the Env-DATA system components within Movebank. 


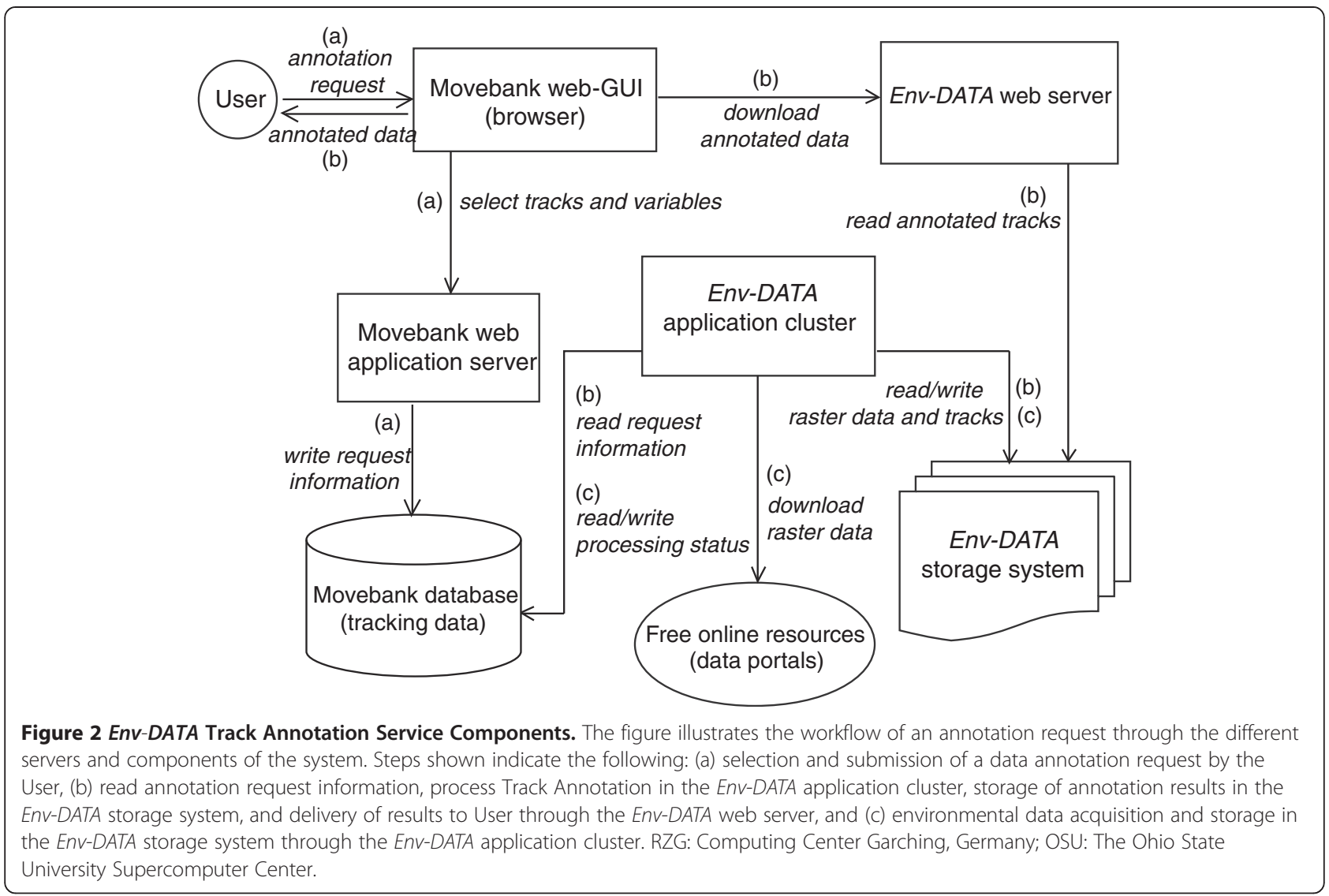

Surface Current Analyses (OSCAR) ocean currents and sea surface temperatures; NASA's Tropical Rainfall Measuring Mission (TRMM) precipitation; normalized difference vegetation index from the AVHRR sensor; ESA's GlobeCover land use and land cover; NASA's ASTERGDEM $30 \mathrm{~m}$ topography; and the Columbia University Human Geography dataset. The raw data are obtained in different formats, such as NetCDF, GRIB, HDF, GeoTIFF, and ASCII. See Table 1 for more details about the datasets. Env-DATA also offers derived variables that are particularly suited to aerial movement studies, such as tail-wind support and uplift availability (Table 1 ).

\section{Track annotation service}

The term "path annotation", borrowed from computer science, is used when additional data about important variables encountered through a particular path are added to the dataset describing an object's trajectory. In the context of animal movement, path (track) annotation includes environmental variables co-located in time and space with the moving organism's coordinates [7]. The Env-DATA Track Annotation Service is the fundamental extension of the Movebank portal that attributes environmental data to each tracking location (in space and time) along a movement path. The service consists of several components as illustrated in Figure 2 and described below.

The Env-DATA application cluster resides on the RZG and OSC servers and is the main core of the system (Figures 1 and 2). Data flow required for the annotation service is handled through the Movebank web application server and Env-DATA web server using MySQL. The annotation service is triggered by a request from the User using the Movebank web-GUI (arrows (a) in Figure 2) and is processed at the Env-DATA application cluster. The annotation results are then stored in the Env-DATA storage system and an email notification, including an http download link, is sent to the user through the Env-DATA web server when data are available for download (arrows (b) in Figure 2). The Env$D A T A$ web server is a dedicated machine that runs a Tomcat web application server and provides an http interface to the service running on the Env-DATA application cluster. The Env-DATA web server functionality is limited to accepting annotation requests, storing them in the database, and delivering the results. All data processing is performed on the Env-DATA application cluster, which is a family of Linux compute nodes.

The annotation service is conducted offline because of the large volumes of data involved. Latency of the service depends on the time required to download the 
Table 1 Available environmental datasets for the trajectory annotation service

\begin{tabular}{|c|c|c|c|c|c|c|c|c|}
\hline Datasets & Data Description & Data Source & $\begin{array}{l}\text { Projection system/ } \\
\text { Grid }\end{array}$ & $\begin{array}{l}\text { Temporal } \\
\text { Coverage }\end{array}$ & $\begin{array}{l}\text { Geographic } \\
\text { coverage } \\
\text { (Latitude/ } \\
\text { Longitude) }\end{array}$ & $\begin{array}{l}\text { Temporal } \\
\text { resolution }\end{array}$ & Spatial resolution & $\begin{array}{l}\text { Data } \\
\text { Format }\end{array}$ \\
\hline $\begin{array}{l}\text { Tropical Rainfall Measuring } \\
\text { Mission (TRMM) [37] }\end{array}$ & $\begin{array}{l}\text { Tropical } \\
\text { precipitation }\end{array}$ & $\begin{array}{l}\text { NASA http://trmm.gsfc.nasa. } \\
\text { gov/ }\end{array}$ & Regular lat/lon grid & 1998- present & $\begin{array}{l}50^{\circ} \mathrm{N}-50^{\circ} \mathrm{S} \\
180^{\circ} \mathrm{E}-180^{\circ} \mathrm{W}\end{array}$ & 3-hour & $0.25^{\circ}$ & $\begin{array}{l}\text { Unformatted } \\
\text { binary }\end{array}$ \\
\hline AVHRR land NDVI [38] & $\begin{array}{l}\text { Normalized } \\
\text { difference } \\
\text { vegetation index } \\
\text { from the AVHRR } \\
\text { (low resolution) } \\
\text { sensor }\end{array}$ & $\begin{array}{l}\text { USGS (USA only) http:// } \\
\text { phenology.cr.usgs.gov/ } \\
\text { get_data_1 km.php NASA } \\
\text { (global) http://glcf.umiacs. } \\
\text { umd.edu/data/gimms/ }\end{array}$ & $\begin{array}{l}\text { Albert's Equal Area } \\
\text { grids }\end{array}$ & $\begin{array}{l}\text { 1989-present, } \\
\text { 1982-present }\end{array}$ & $\begin{array}{l}\text { CONUS, } 90^{\circ} \\
\text { N- } 90^{\circ} \mathrm{S} 180^{\circ} \\
\mathrm{E}-180^{\circ} \mathrm{W}\end{array}$ & 1-week, 2-week & $\begin{array}{l}1 \mathrm{~km} \text { (USA), } \\
8 \mathrm{~km} \text { (global) }\end{array}$ & $\begin{array}{l}\text { Unformatted } \\
\text { binary }\end{array}$ \\
\hline NCEP Global Reanalysis 2 [39] & $\begin{array}{l}\text { Global weather } \\
\text { reanalysis }\end{array}$ & $\begin{array}{l}\text { NOAA http://www.esrl.noaa. } \\
\text { gov/psd/data/gridded/data. } \\
\text { ncep.reanalysis2.html }\end{array}$ & $\begin{array}{l}\text { Regular (non-Gaussian) } \\
\text { grid }\end{array}$ & 1948-present & $\begin{array}{l}90^{\circ} \mathrm{N}-90^{\circ} \mathrm{S} \\
180^{\circ} \mathrm{E}-180^{\circ} \mathrm{W}\end{array}$ & 6-hour & $2.5^{\circ}(208 \mathrm{~km})$ & NetCDF \\
\hline $\begin{array}{l}\text { North American Regional } \\
\text { Reanalysis (NARR) [40] }\end{array}$ & $\begin{array}{l}\text { Regional (North } \\
\text { America only) } \\
\text { weather reanalysis }\end{array}$ & $\begin{array}{l}\text { NOAA http://www.emc.ncep. } \\
\text { noaa.gov/mmb/rreanl/ }\end{array}$ & $\begin{array}{l}\text { Lambert Conformal, } \\
\text { Conic Grids }\end{array}$ & 1979-present & $\begin{array}{l}90^{\circ} \mathrm{N}-1^{\circ} \mathrm{N} \\
0^{\circ}-170 \mathrm{~W}^{\circ}\end{array}$ & 3-hour & $32 \mathrm{~km}\left(\right.$ at $\left.40^{\circ} \mathrm{N}\right)$ & GRIB \\
\hline ECMWF Reanalysis [41] & $\begin{array}{l}\text { Global weather } \\
\text { reanalysis }\end{array}$ & $\begin{array}{l}\text { ECMWF http://www.ecmwf. } \\
\text { int/ }\end{array}$ & Regular grid & 1979-present & $\begin{array}{l}89.463^{\circ} \mathrm{N}- \\
89.463^{\circ} \mathrm{S} \\
180^{\circ} \mathrm{E}-180^{\circ} \mathrm{W}\end{array}$ & 6-hour & $0.7^{\circ}$ & GRIB \\
\hline MODIS Land & $\begin{array}{l}\text { Earth-surface, } \\
\text { reflectivity and } \\
\text { vegetation } \\
\text { variables }\end{array}$ & NASA https://lpdaac.usgs.gov/ & $\begin{array}{l}\text { Geographic/ Sinusoidal } \\
\text { grid }\end{array}$ & 2002-2012 & $\begin{array}{l}90^{\circ} \mathrm{N}-90^{\circ} \mathrm{S} \\
180^{\circ} \mathrm{E}-180^{\circ} \mathrm{W}\end{array}$ & $\begin{array}{l}\text { Daily, 8-day, } \\
\text { 16-day, monthly }\end{array}$ & $5.6 \mathrm{~km}\left(0.05^{\circ}\right)$ & HDF- EOS \\
\hline MODIS Ocean & $\begin{array}{l}\text { Ocean surface, } \\
\text { color, and } \\
\text { productivity } \\
\text { variables }\end{array}$ & $\begin{array}{l}\text { NASA http://oceancolor.gsfc. } \\
\text { nasa.gov/ }\end{array}$ & Cylindrical Equidistant & & & & $4 \mathrm{~km}, 9 \mathrm{~km}$ & HDF- EOS \\
\hline MODIS Snow & $\begin{array}{l}\text { Snow and ice } \\
\text { variables }\end{array}$ & $\begin{array}{l}\text { NASA http://modis-snow-ice. } \\
\text { gsfc.nasa.gov/ }\end{array}$ & Cylindrical Equidistant & & & & $1 \mathrm{Km}, 4 \mathrm{Km}$ & HDF- EOS \\
\hline Ocean productivity [42] & $\begin{array}{l}\text { Ocean net primary } \\
\text { productivity (NPP) } \\
\text { reanalysis }\end{array}$ & $\begin{array}{l}\text { http://www.science. } \\
\text { oregonstate.edu/ocean. } \\
\text { productivity/ }\end{array}$ & $\begin{array}{l}\text { Equidistant Cylindrical } \\
\text { projection, lat/lon grid }\end{array}$ & 1997-2009 & $\begin{array}{l}90^{\circ} \mathrm{N}-90^{\circ} \mathrm{S} \\
180^{\circ} \mathrm{E}-180^{\circ} \mathrm{W}\end{array}$ & 8-day, monthly & $\begin{array}{l}\text { Grid sizes } 1080 \times 2160 \\
\text { (1/6 degree) } 2160 \times 4320 \\
\text { (1/12 degree) }\end{array}$ & HDF \\
\hline ASTER GDEM & $\begin{array}{l}\text { Very high- } \\
\text { resolution } \\
\text { topography }\end{array}$ & $\begin{array}{l}\text { USGS http://asterweb.jpl.nasa. } \\
\text { gov/gdem.asp }\end{array}$ & $\begin{array}{l}\text { Regular grid, (WGS84 } \\
\text { ellipsoid) }\end{array}$ & & $\begin{array}{l}83^{\circ} \mathrm{N}-83^{\circ} \mathrm{S} \\
180^{\circ} \mathrm{E}-180^{\circ} \mathrm{W}\end{array}$ & & 1 arc-second & GeoTIFF \\
\hline SRTM [43] & $\begin{array}{l}\text { High resolution } \\
\text { topography }\end{array}$ & $\begin{array}{l}\text { NASA http://www.cgiar-csi. } \\
\text { org/data/srtm-90m-digital- } \\
\text { elevation-database-v4-1 }\end{array}$ & $\begin{array}{l}\text { Regular grid, (WGS84 } \\
\text { ellipsoid) }\end{array}$ & & $\begin{array}{l}60^{\circ} \mathrm{N}-60^{\circ} \mathrm{S} \\
180^{\circ} \mathrm{E}-180^{\circ} \mathrm{W}\end{array}$ & & 3 arc-second & HGT \\
\hline GlobCover & $\begin{array}{l}\text { Land cover and } \\
\text { land-use type }\end{array}$ & $\begin{array}{l}\text { ESA http://dup.esrin.esa.it/ } \\
\text { prjs/prjs68.php }\end{array}$ & $\begin{array}{l}\text { Plate-Carrée projection } \\
\text { (WGS84 ellipsoid) }\end{array}$ & 2009 & $\begin{array}{l}90^{\circ} \mathrm{N}-65^{\circ} \mathrm{S} \\
180^{\circ} \mathrm{E}-180^{\circ} \mathrm{W}\end{array}$ & & 20 arc-seconds & $\mathrm{HDF}$ \\
\hline $\begin{array}{l}\text { Socioeconomic data } \\
\text { (Population Density Grid) }\end{array}$ & Human geography & $\begin{array}{l}\text { http://sedac.ciesin.columbia. } \\
\text { edu/gpw/global.jsp }\end{array}$ & $\begin{array}{l}\text { Regular grid (WGS84 } \\
\text { ellipsoid) }\end{array}$ & 1990-2010 & $\begin{array}{l}85^{\circ} \mathrm{N}-58^{\circ} \mathrm{S} \\
180^{\circ} \mathrm{E}-180^{\circ} \mathrm{W}\end{array}$ & 5 years & 30 arc-second $(1 \mathrm{~km})$ & ASCII \\
\hline
\end{tabular}


Table 1 Available environmental datasets for the trajectory annotation service (Continued)

\begin{tabular}{|c|c|c|c|c|c|c|c|c|}
\hline $\begin{array}{l}\text { Ocean Surface Current } \\
\text { Reanalysis (OSCAR) }\end{array}$ & $\begin{array}{l}\text { Ocean surface } \\
\text { currents }\end{array}$ & $\begin{array}{l}\text { NASA http://www.oscar.noaa. } \\
\text { gov/ }\end{array}$ & Regular grid & 1993-present & $\begin{array}{l}60^{\circ} \mathrm{N}-60^{\circ} \mathrm{S} \\
180^{\circ} \mathrm{E}-180^{\circ} \mathrm{W}\end{array}$ & 5-day, monthly & 1 degree, $1 / 3$ degree & NetCDF \\
\hline ETOPO1 & $\begin{array}{l}\text { Ice surface and } \\
\text { bedrock }\end{array}$ & $\begin{array}{l}\text { NASA http://www.ngdc.noaa. } \\
\text { gov/mgg/global/global.html }\end{array}$ & $\begin{array}{l}\text { Regular grid (WGS84 } \\
\text { ellipsoid) }\end{array}$ & 1940-2008 & $\begin{array}{l}90^{\circ} \mathrm{N}-90^{\circ} \mathrm{S} \\
180^{\circ} \mathrm{E}-180^{\circ} \mathrm{W}\end{array}$ & & 1 arc-minute & NetCDF \\
\hline $\begin{array}{l}\text { Distance to the Nearest } \\
\text { Coast }\end{array}$ & $\begin{array}{l}\text { Distance to the } \\
\text { nearest coast }\end{array}$ & $\begin{array}{l}\text { NASA http://oceancolor.gsfc. } \\
\text { nasa.gov/DOCS/ } \\
\text { DistFromCoast/ }\end{array}$ & Regular grid & & $\begin{array}{l}90^{\circ} \mathrm{N}-90^{\circ} \mathrm{S} \\
180^{\circ} \mathrm{E}-180^{\circ} \mathrm{W}\end{array}$ & & $0.04^{\circ} 0.01^{\circ}$ & $\begin{array}{l}\text { Text file, } \\
\text { GeoTiff }\end{array}$ \\
\hline $\begin{array}{l}\text { Derived wind variables for } \\
\text { flight }\end{array}$ & $\begin{array}{l}\text { Tail-wind support } \\
\text { and cross wind } \\
\text { [36]; Thermal and } \\
\text { orographic uplift } \\
\text { [5] }\end{array}$ & $\begin{array}{l}\text { Calculated derived variables, } \\
\text { based on ECMWF or NCEP } \\
\text { data }\end{array}$ & Regular grid & 1979-present & $\begin{array}{l}89.463^{\circ} \mathrm{N}- \\
89.463^{\circ} \mathrm{S} \\
180^{\circ} \mathrm{E}-180^{\circ} \mathrm{W}\end{array}$ & 6-hour & $0.7^{\circ}$ & ASCII \\
\hline $\begin{array}{l}\text { Derived topographic } \\
\text { variables }\end{array}$ & $\begin{array}{l}\text { Slope and aspect } \\
\text { [25]; Rugosity [44] }\end{array}$ & $\begin{array}{l}\text { Calculated derived variables, } \\
\text { based on ASTERGDEM }\end{array}$ & Regular grid & & $\begin{array}{l}83^{\circ} \mathrm{N}-83^{\circ} \mathrm{S} \\
180^{\circ} \mathrm{E}-180^{\circ} \mathrm{W}\end{array}$ & & 1 arc-second & ASCII \\
\hline
\end{tabular}


necessary environmental data. The annotation workflow involves several steps, described below.

\section{Annotation request}

Users may request two types of annotation: (1) annotation of a gridded geographic area or (2) annotation of a set of trajectories. For trajectory annotations, the output spatial and temporal resolutions and extent are determined by the system according to the spatial and temporal constraints of the input trajectories.

A trajectory annotation request starts with the selection of one or more animal tracks from an existing usercreated study in Movebank. After selecting the trajectories the user is asked to choose a subset of environmental variables (for example, window (1) in Figure 3). There are two methods (represented by separate tabs) for browsing and selecting variables (window (1) in Figure 3): (1) select variables by source, with environmental variables organized according to their original satellite missions or dataset portal (e.g. MODIS or ECMWF, see Table 1 for complete list); or (2) select variables by type, where the variables are organized according to their geophysical composition (e.g. weather, topography, earth surface and vegetation, ocean). Both methods lead the user through a hierarchical classification (e.g. weather $\rightarrow$ temperature $\rightarrow$ surface temperature $\rightarrow$ NCEP air temp at $10 \mathrm{~m}$ ) to the point where specific variables can be selected and added to the annotation request. Summary information about each variable and links to source documentation are available from the interface. Next, the user chooses an interpolation method for each environmental variable (window (2) in Figure 3). The annotation service provides three interpolation methods: nearest neighbor, bilinear, and inverse weighted distance, as explained in "Data Interpolation" below.

For annotations of geographic areas, the user specifies the coordinates of four corners of a region of interest, a coordinate reference system (e.g. WGS84 lon/lat), required timestamps (e.g. as "yyyy-MM-dd HH:mm:ss", comma separated), and a spatial resolution for the target grid (in number of pixels). Data will be interpolated if the requested resolution is higher than the native resolution of the dataset. The result is a bundle of mapped data that can be read for numerical analysis (for example by a niche model, such as Maxent), or used as GeoTiff images or as KML image overlays in Google Earth.

After selecting the desired information for either annotation method, the user provides an e-mail address to which a link to the completed data file will be mailed and submits the request.

\section{Data acquisition}

As the combined volume of globally available environmental data is on the order of petabytes, it is not feasible to locally mirror all of the source environmental data. Instead, the Env-DATA application cluster applies a caching strategy to retain the most frequently accessed data and download any other data upon request if it is not already locally stored at the Env-DATA storage system (arrows (c) in Figure 2). New data requests (provided as a list of locations, times and variables) are translated to lists of needed data sources, sorted according to data service, variable, timestamp and scene (i.e. a raster tile). Multiple data sources are listed when

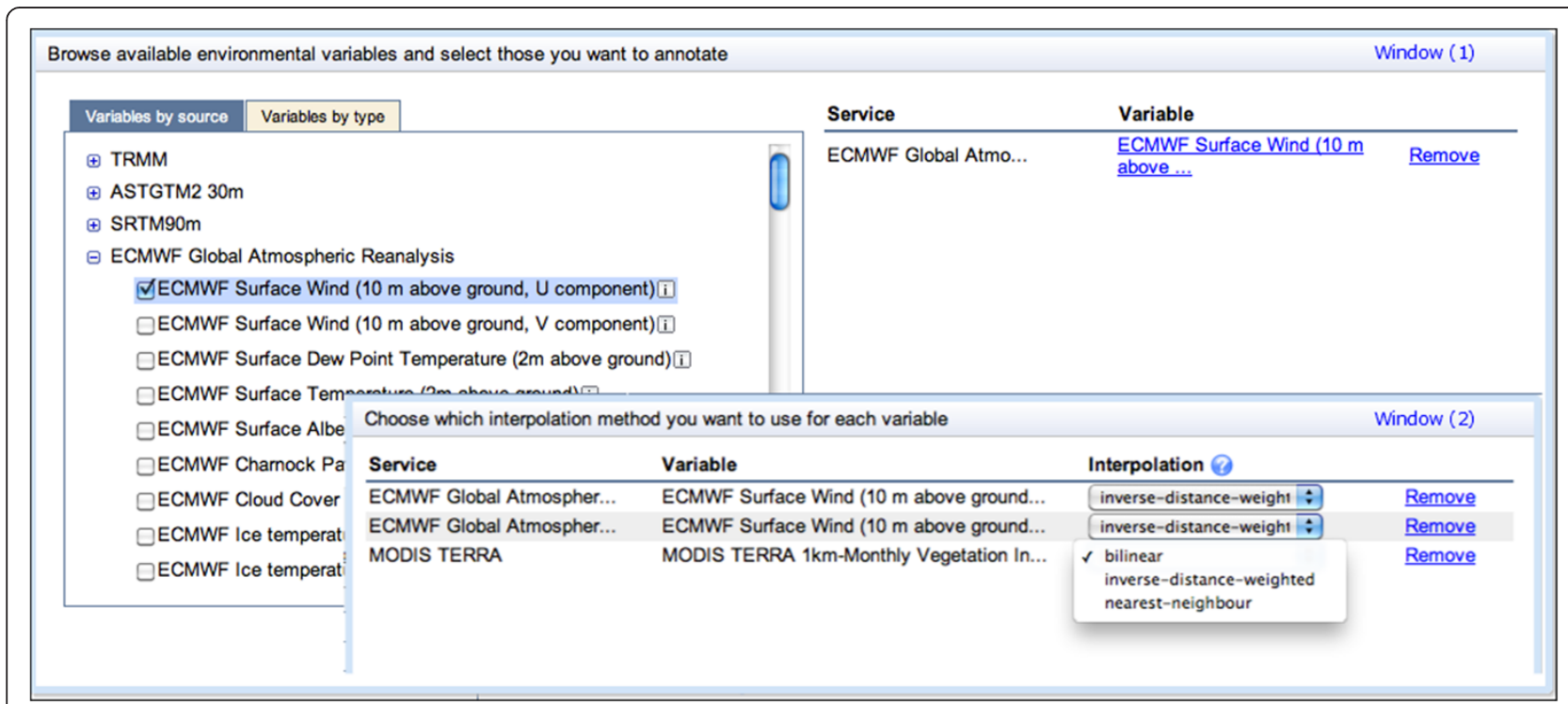

Figure 3 An example for the graphical user interface (GUI) that serves the annotation system users. The figure illustrates an annotation request for the data in the variable "surface wind (10m above ground, $\mathrm{U}$ component)" from the global weather reanalysis dataset ECMWF (see Table 1 for more details), and selection of interpolation methods for each requested variable. 
the location in the movement path requires interpolation between scenes and/or in time, or when derived variables (such as thermal uplift) require a combination of several input environmental variables. The data-sources list is compared with the stored metadata table and data that are not stored locally are requested from their provider using an $\mathrm{ftp} / \mathrm{http}$, or OPeNDAP interface. The system ranks each scene according to the frequency at which it has been accessed since download. The least accessed scenes are deleted when space is needed for new data.

\section{Data retrieval, indexing, and transformation strategies}

The environmental data are acquired in a variety of data formats (e.g. GeoTIFF, NetCDF, HDF, GRIB). Prior to the annotation, Env-DATA extracts the required variables from the original data structure using available Java libraries associated with the data formats. For each variable an $n$-dimensional grid is defined $(1 \leq n \leq 4$, possible dimensions are $x, y, z, t)$ which spans the complete domain of definition of the variable. Each point in the grid is assigned a tile index and tile indices are mapped to the names of files that contain the data for a tile. When a set of points is submitted for annotation by the Env$D A T A$ system, each point is transformed to the coordinate reference system of the annotation variable using proper projection techniques. A set of neighboring grid points is then determined and the names of the files containing data for these grid points are identified. For those files not already stored in the Env-DATA storage system, an asynchronous job is started to download them from the original source. When the system runs out of disc space for storing new files, a garbage collection job deletes files following a least recently used (LRU)based algorithm. Track annotation and interpolation starts when all required files have been downloaded. Data files are read in blocks and blocks are cached in an in-memory LRU cache. The block structure is chosen to match the physical structure of the underlying file in order to optimize read performance. In order to optimize cache use, data points are sorted according to the files they require for annotation and the within-file block structure.

Separate processing steps (e.g. pre-processing, data download, garbage collection and track annotation) are performed in parallel on a pool of compute nodes at the Env-DATA application cluster, while resource access is coordinated by a bespoke locking system implemented on MySQL.

\section{Data interpolation}

Once all necessary data sources are locally available, the environmental data are interpolated along all trajectory points. Prior to the interpolation, the trajectories are first transformed to the native grid of the environmental variables (e.g. the Sinusoidal grid for MODIS or Lambert Conformal for NARR), if required. After the transformation, for each point along a trajectory, the interpolation first is applied in space, then in time. For each trajectory point $p_{i}\left(x_{i}, y_{i}, t_{i}\right)$, four adjacent pixels (or more if necessary) are located in the global grid of environmental data in space (Figure 4a) at two temporal timestamps before and after $t_{i}$ (Figure $4 \mathrm{~b}$ ). The values of the four neighbor pixels (i.e. $v_{1} \ldots v_{4}$ and $v_{1}{ }^{\prime} \ldots v_{4}{ }^{\prime}$ ) at two timestamps $t$ and $t^{\prime}$ are then extracted and used to compute an interpolated value for the trajectory point $p_{i}$.

The system allows three types of interpolation in space: nearest neighbor, bilinear, and inverse weighted distance $[45,46]$, and two types in time: nearest neighbor and inverse weighted distance. The user can apply different methods of interpolation to space and to time. However, the available interpolation strategy differs according to the type of data. For instance, for categorical data, such as land-use type, only the nearest neighbor interpolation can be applied, whereas for continuousnumeric data types either a nearest neighbor, bilinear (in regular grids), or inverse weighted distance interpolation can be selected based on the resolution of data $[45,46]$. Spatial distances used by the nearest neighbor and inverse weighted distance interpolations are calculated as great circle distances on the WGS84 ellipsoid.

\section{Results delivery}

The annotated trajectories are delivered to the user via http download in comma-separated values (csv) format, and gridded geographic areas as GeoTiff or KML images. The user receives an e-mail with a link when the download is ready. The annotated data are stored in the Env-DATA storage system at OSU and delivered to the user through the Env-DATA web server (cf. arrow (b) in Figure 2). Metadata for the output is uniform across different annotation requests and movement data types, which simplifies linking the output with further analysis tools. A user-group community in Movebank provides a place to exchange user-developed codes and statistical and analytical methods, suggest knowledge discovery and data mining methods, or comment on existing tools and research challenges.

\section{Case study: Galapagos albatross (phoebastria irrorata)}

This case study illustrates an application of the Env-DATA System to examine environmental factors associated with the movements of nine Galapagos Albatrosses (Phoebastria irrorata), tracked from June to September 2008.

\section{Methods - movement data collection and annotation} The original tracking data were collected from birds breeding at two sites on Isla Española, Punta Cevallos 


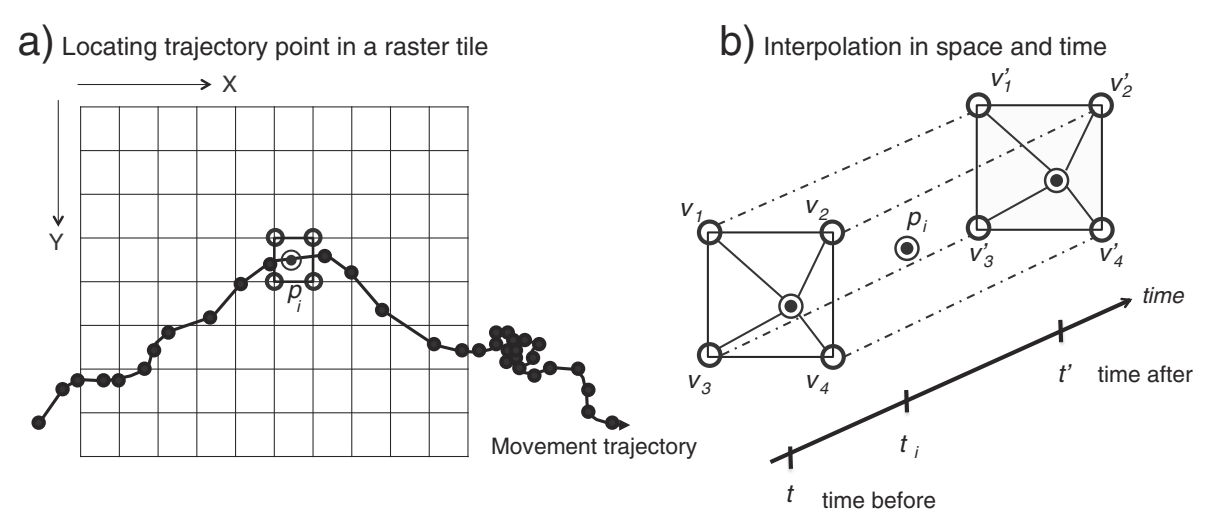

Figure 4 Interpolation in space and time. (a) The variable data for track-point $P_{i}$ is first interpolated in space (using one of several interpolation methods) based on the data from the available points in the environmental dataset native grid around $P_{i \text {. }}(\mathbf{b})$ Similar spatial interpolations are conducted at the two nearest available points in time, the nearest before and nearest after the timestamp of the track-point $P_{j}$. Then, the two interpolated spatial values are interpolated in time to the timestamp of $\mathrm{P}_{i}$.

$\left(1.39^{\circ} \mathrm{S}, 89.62^{\circ} \mathrm{W}\right)$ and Punta Suarez $\left(1.38^{\circ} \mathrm{S}, 89.75^{\circ} \mathrm{W}\right)$, as well as a small island close to the Ecuadorian mainland, Isla de la Plata $\left(1.58^{\circ} \mathrm{S}, 81.15^{\circ} \mathrm{W}\right)$. The birds were tracked throughout the entire breeding season. GPS loggers were deployed on 28 adult albatrosses at the beginning of incubation period. The loggers weighed $22 \mathrm{~g}$ with a 9-month battery life and were designed and produced by e-obs GmbH (Munich, Germany). Units were programmed to record GPS locations every 90 minutes. Units were attached to taped bundles of dorsal feathers and secured with cable ties. Data from GPS units were downloaded remotely via an ultra-high frequency (UHF) radio link to a stationary base station that was installed in the vicinity of equipped bird nests at each separate colony. A base station consists of a UHF antenna, a receiver with flash memory and two 6 volt 12 amp-hour batteries. The base station begins to upload data when any unit (or equipped bird) comes within $1000 \mathrm{~m}$ of the station. This system has the advantage of allowing data to be retrieved automatically without physically recovering the tag, reducing handling-induced stress to the birds and labor required to collect data in the field. Every four weeks a researcher would go to sites to retrieve data from base stations, change batteries and perform general maintenance duties. On Isla Española, tags were deployed on 23 June 2008 at Punta Cevallos and 31 May 2008 at Punta Suarez, and data were retrieved from base stations on 23 June, 21 July, 12 August and 18 September 2008. On Isla de la Plata, tags were deployed on 7-24 June 2008, data were downloaded on 7 July, 4 August, 1 September, and 6 October of 2008, and loggers were recovered on 7 October.

For the purpose of this case study, we used tracking data from nine albatrosses that made extensive movements for almost the entire period from June to September 2008.
The tracks were segmented to transit flights from/to the Galapagos Islands and the Peruvian coastal foraging segments. The transit flights are segmented according the flight speed obtained from GPS points (speed $>5 \mathrm{~m} / \mathrm{s}$ ) between longitudes $90^{\circ} \mathrm{W}$ and $82.5^{\circ} \mathrm{W}$. The Peruvian coastal foraging area is defined as areas between longitudes $82.5^{\circ}$ $\mathrm{W}$ and $75^{\circ} \mathrm{W}$. Using Env-DATA, the nine albatross tracks were annotated with wind speed $(\mathrm{m} / \mathrm{s})$ and wind direction (degrees from North) computed from $\mathrm{u}$ - and v-wind components obtained from the NCEP Reanalysis 2 dataset, and Ocean Net Primary Production (NPP) data from Oregon State University (Table 1). For the annotation 6-hour, $2.5^{\circ}$ NCEP Reanalysis 2, and 8-day, 2160x4320 ocean NPP datasets are used (cf. Table 1).

\section{Results and discussion}

Figures 5, 6, 7, and 8 illustrate the visual exploration tools from the Knowledge Discovery and Visualization service package of Env-DATA. R code for the generation of these plots is provided in the supporting material (Additional File 1). Figure 5a shows the nine Galapagos Albatross trajectories annotated with 8-day ocean NPP (cf. Function 1, Additional File 1) and Figure 5b shows a gridded geographical area of MODIS chlorophyll-a concentration during one month in the nesting season in 2008, provided as a KML file and plotted using Google Earth. The albatrosses flew to the Peruvian coast to forage where ocean productivity was high. Figure 6 facilitates the comparison of available NPP versus NPP use along flight tracks of the nine albatrosses (the $3 \mathrm{D}$ plot is generated using Functions 3, Additional File 1). Figure 6a-b shows the distribution of ocean NPP available at the coastal area of Peru-between $82.5^{\circ} \mathrm{W}, 12^{\circ} \mathrm{S}$ and $75^{\circ} \mathrm{W}, 4^{\circ} \mathrm{S}$ - and around the Galapagos Islands-between $95^{\circ} \mathrm{W}, 2.5^{\circ} \mathrm{S}$ and $90^{\circ} \mathrm{W}, 2.5^{\circ} \mathrm{N}$. To illustrate the availability of ocean NPP 

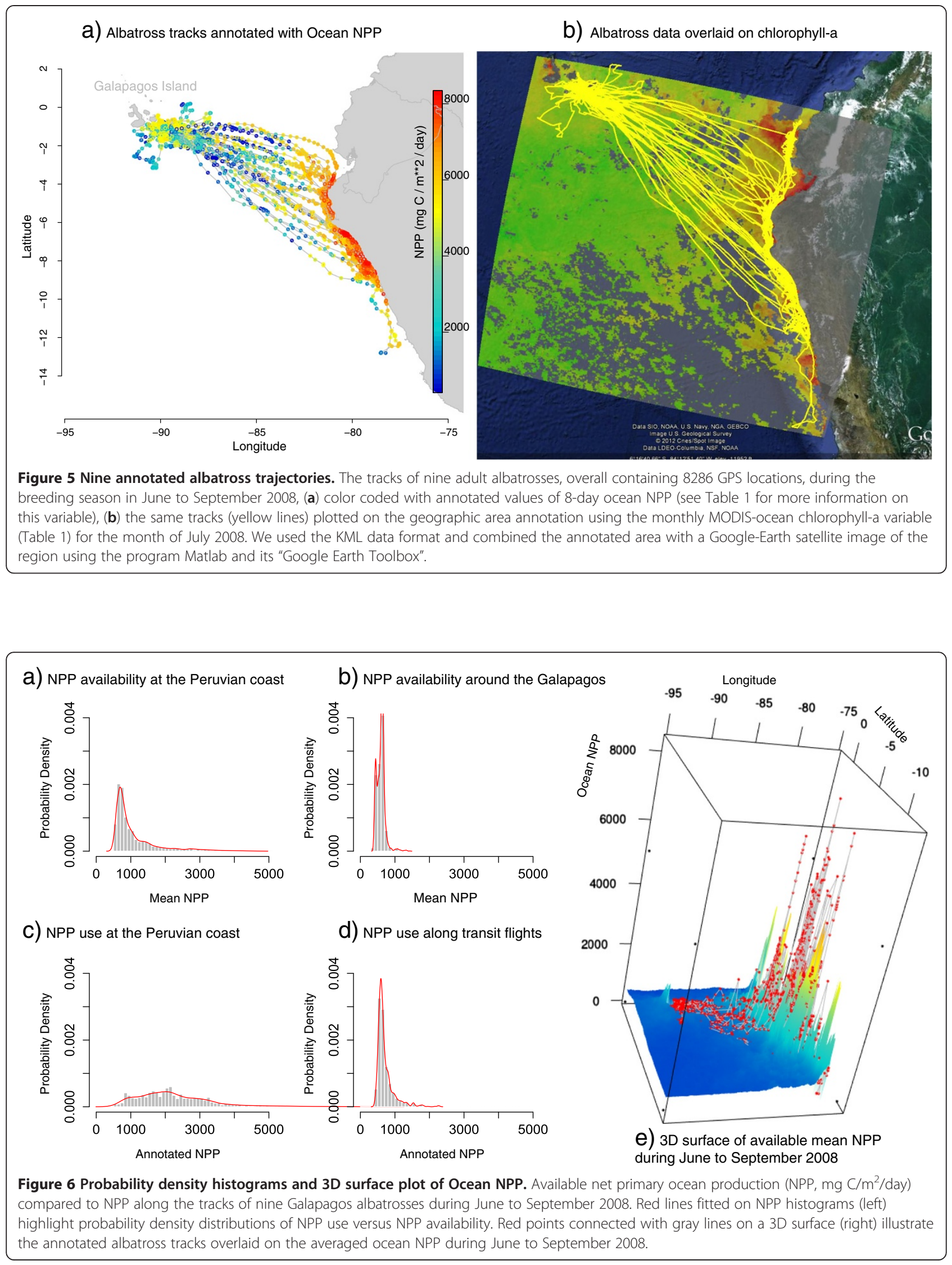


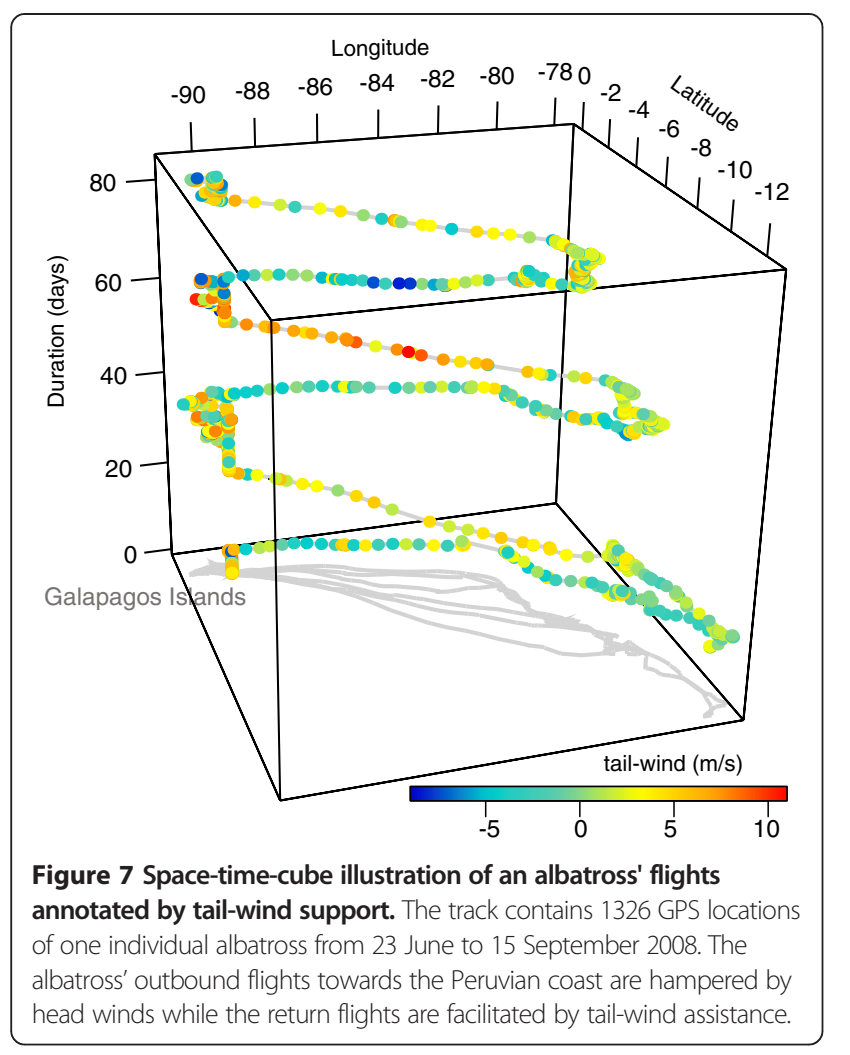

(Figure 6a-b, Figure 6e), the 8-day NPP datasets are averaged over the period of June-September 2008 in the native grid. Figure $6 \mathrm{c}-\mathrm{d}$ shows probability density histograms of annotated ocean NPP values along track segments during foraging flight along the Peruvian coast and along flight tracks around the Galapagos, respectively. In addition, Figure 6e provides a 3D visualization of the available NPP versus NPP use along the actual flight tracks (plotted using Function 3, Additional File 1). The NPP histogram constructed from locations along the foraging flight (what was used) illustrates a bias toward high NPP values (Figure 6c), even when compared to the availability near the coast (Figure 6a), which suggests that albatrosses might carefully choose times and locations to forage where NPP is high. However, the similarity between the NPP use and availability histograms around the islands suggests that they do not show preferences for high NPPs along transit flights between the foraging areas and the nesting grounds.

These findings are in accordance with previous studies showing that parents make long-range trips to preferred, productive areas [47].

We use a space-time-cube visualization to illustrate the role of wind on the albatross' flight patterns (see Figure 7, Function 2, Additional File 1). Recent studies suggest that

a) Albatross track annotated with tail-wind support

b) Albatross track annotated with side-wind
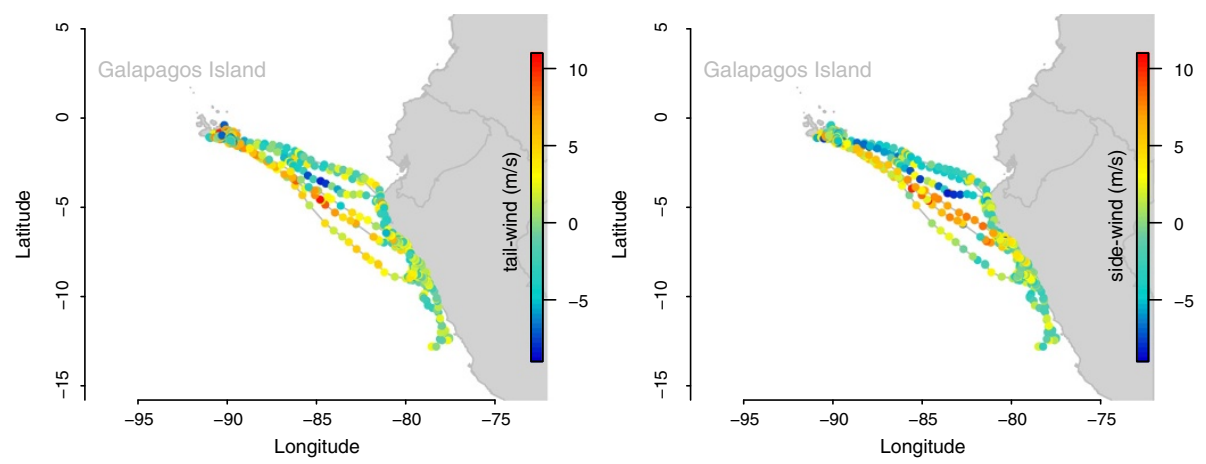

C) Histogram of tail-wind support

d) Histogram of side-wind
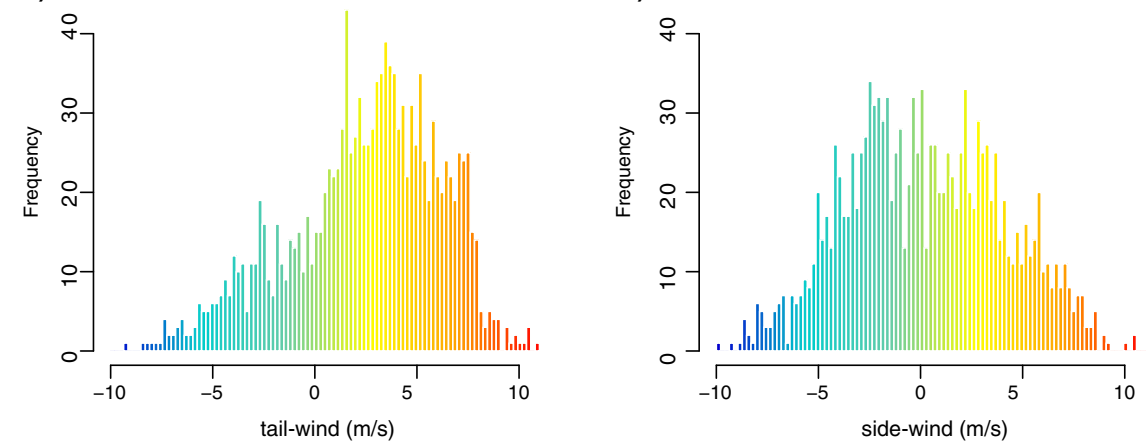

Figure 8 Map (top) and histogram (bottom) illustration of an albatross' flights annotated by tail-wind support and side-wind (cross wind).The track contains 1326 GPS locations of one individual albatross from 23 June to 15 September 2008. 
wind was an important factor in determining migration and short-term flight patterns of pelagic birds [4,24,36,48]. Here, we show how Env-DATA annotation can assist an investigation of wind dependencies and flow assistance. Figures 7 and 8 show a single albatross trajectory annotated by tail-wind support and side-wind (cross wind), two derived variables (Table 1) computed using wind direction and wind speed and movement direction (flight heading) of the albatross along its flight path, based on the formulation from $[24,36]$. The space-time-cube illustrates how wind assistance facilitates the albatross' flights toward the Galapagos Islands (orange to red colors represent higher wind assistance), while the flights to the coast are often challenged by head wind (aquamarine to blue colors represent wind resistance). The flight pattern in Figures 7 and 8 is characteristic to most other flight tracks in our albatross dataset. As seen in Figure 7 and Figure $8 \mathrm{a}-\mathrm{b}$, the albatross repeatedly takes a more northern route to the coast relying mostly on side winds, and then moves south (presumably foraging) before returning to the Galapagos Islands using a tailwind assisted route (cf. Figure 8a and Figure 8c). The observed clock-wise pattern is in accordance with previous findings $[4,48]$. Weimerskirch et. al [48] found that albatrosses prefer tail or side winds and therefore use predictable weather systems to fly in large looping tracks; when going south movements are in a clockwise direction. This enables albatrosses to achieve high speeds while expending little energy. The travel direction towards continental South America and back to the Galapagos undertaken by waved albatross means they almost always have side-winds (cf. Figure $8 \mathrm{~b}$ and Figure 8d).

\section{Conclusions}

We presented the Environmental-Data Automated Track Annotation (Env-DATA) System, an openly available portal within Movebank (www.movebank.org), and illustrated how the system assists the discovery of environmental conditions associated with animal movements. As compared to the existing RNCEP package, that provides access to, organization, and visualization of atmospheric NCEP/NCAR datasets, the Env-DATA annotation service streamlines the co-registration of animal tracking data with a diverse range of environmental variables obtained from satellite remote sensing products and global reanalysis models including the MODIS ecological, ocean, land cover and land use data sets, the NCEP/NCAR and ECMWF weather reanalysis datasets, high-resolution Digital Elevation Models (DEMs), and ecological and human-socioeconomic reanalyses (e.g. the Population Density Grid). This project has overcome the numerous technical and methodological challenges in order to enable processing of a large array of remote sensing, weather and geographical data for the analysis of animal movement tracks:

- optimizing storage and retrieval times for a very large dataset of environmental variables from multiple data providers,

- applying effective interpolation techniques in order to maintain the link between animal tracks and their embedding environment in space and time,

- applying suitable spatiotemporal indexing strategies for data retrieval, and

- maintaining a large database of remote sensing data.

In addition, our system is intended as a general tool that can be used by researchers at all levels of technical ability for a wide range of animal movement data types and research questions. Thus additional challenges were:

- establishing linkages between heterogeneous environmental and movement data, obtained from various sources, collected in different spatial and temporal resolutions and scales; and

- developing a user-friendly interface within Movebank to allow users to browse, access documentation about variables and source datasets, and select and request annotated data.

In addition to the main annotation service, we are currently developing the Knowledge Discovery and Visualization Service and the Track Simulation Service within the Env-DATA System. In future releases, we aim to exploit deterministic and probabilistic computational GIS methods, spatiotemporal data mining techniques, and well-known statistical approaches, with the underlying goal to discover patterns and structures among the movements of animals.

\section{Availability of supporting data}

The albatross dataset supporting the results of this article is accessible through DOI: 10.5441/001/1.3hp3s250 and can also be viewed at www.movebank.org in the study "Galapagos Albatrosses". The R scripts used for generating Figures $5-8$ in this article are provided in Additional File 1.

\section{Additional file}

Additional file 1: R scripts of visualization tools.

\section{Competing interest}

The authors declare that they have no competing interests.

\section{Author's contribution}

SD drafted the manuscript, prepared the figures, analyzed the case study data, and participated in development of the system. GB conceived the 
study, coordinated the project. RW implemented the system and participated in the design of the study. SCD participated in the coordination of the study. SD, RK, DD, JH, DB, and MW participated in the design and coordination of the study. SD, GB, RW, DD and SCD contributed to the writing. SC provided the albatross data and contributed to the case study. All authors participated in editing the manuscript.

\section{Acknowledgment}

We thank Keith Bildstein, Ran Nathan, Kamran Safi, Nir Sapir, John Takekawa, Zhenhui Li, Richard Lanctot, Steve Lewis, Stephen Yezerinac, Carol McIntyre, Erica Craig, Jean-Francois Therrien, Josh Adams, Mark Fuller, and Ron Therrien for ideas and collaboration that helped shape and test the system. We also thank Martin Storhas and Matthias Berger for their work on developing the user interface for the Env-DATA System. This research was funded by NASA under grant \#NNX11AP61G. Super computer service at The Ohio Supercomputer Center was provided under OSC grant \#PAS0626-1. GB was supported in part by the U.S. National Science Foundation grant IOS-1145952. Any opinions, findings, and conclusions or recommendations expressed in this material are those of the author(s) and do not necessarily reflect the views of the National Science Foundation. Use of trade names does not reflect endorsement by the U.S. Government. Galapagos Albatross data used for the case study were collected with permission and support of the Galapagos National Park Service.

\section{Author details}

'Department of Civil, Environmental \& Geodetic Engineering, The Ohio State University, 475 Hitchcock Hall, 2070 Neil Avenue, Columbus, USA. ${ }^{2}$ Max Planck Institute for Ornithology, Radolfzell, Germany. ${ }^{3} \mathrm{NC}$ Museum of Natural Sciences \& NC State University, Raleigh, USA. ${ }^{4}$ U.S. Geological Survey, Alaska Science Center, Juneau, USA. ${ }^{5}$ University of Illinois at Urbana-Champaign, Urbana, USA. ${ }^{6}$ Lafayette College, Easton, USA. ${ }^{7}$ Department of Biology, University of Konstanz, Konstanz, Germany.

Received: 28 December 2012 Accepted: 15 March 2013 Published: 3 July 2013

\section{References}

1. Nathan R, Getz WM, Revilla E, Holyoak M, Kadmon R, Saltz D, Smouse PE: A movement ecology paradigm for unifying organismal movement research. Proc Natl Acad Sci U S A 2008, 105:19052-19059.

2. Shamoun-Baranes J, Bouten W, Van Loon EE: Integrating meteorology into research on migration. Integr Comp Biol 2010, 50:280-292.

3. Gordon DM: Variation and Change in Behavioral Ecology. Ecology 1991, 72:1196-1203.

4. Chapman JW, Klaassen RHG, Drake VA, Fossette S, Hays GC, Metcalfe JD, Reynolds AM, Reynolds DR, Alerstam T: Animal orientation strategies for movement in flows. Curr Biol 2011, 21:R861-R870.

5. Bohrer G, Brandes D, Mandel JT, Bildstein KL, Miller TA, Lanzone M, Katzner T, Maisonneuve C, Tremblay JA: Estimating updraft velocity components over large spatial scales: contrasting migration strategies of golden eagles and turkey vultures. Ecol Lett 2012, 15:96-103.

6. Mandel JT, Bildstein KL, Bohrer G, Winkler DW: Movement ecology of migration in turkey vultures. Proc Natl Acad Sci U S A 2008, 105:19102-19107.

7. Mandel JT, Bohrer G, Winkler DW, Barber DR, Houston CS, Bildstein KL: Migration path annotation: cross-continental study of migration-flight response to environmental conditions. Ecological applications: a publication of the Ecological Society of America 2011, 21:2258-2268.

8. Bowlin MS, Bisson I-A, Shamoun-Baranes J, Reichard JD, Sapir N, Marra PP, Kunz TH, Wilcove DS, Hedenström A, Guglielmo CG, Åkesson S, Ramenofsky $\mathrm{M}$, Wikelski M: Grand challenges in migration biology. Integr Comp Biol 2010, 50:261-279.

9. Vanak AT, Thaker M, Slotow R: Do fences create an edge-effect on the movement patterns of a highly mobile mega-herbivore? Biol Conserv 2010, 143:2631-2637.

10. Sapir N, Wikelski M, Avissar R, Nathan R: Timing and flight mode of departure in migrating European bee-eaters in relation to multi-scale meteorological processes. Behav Ecol Sociobiol 2011, 65:1353-1365.

11. Sapir N, Horvitz N, Wikelski M, Avissar R, Mahrer Y, Nathan R: Migration by soaring or flapping: numerical atmospheric simulations reveal that turbulence kinetic energy dictates bee-eater flight mode. Proceedings Biological sciences / The Royal Society 2011, 278:3380-3386.
12. Nathan R, Spiegel O, Fortmann-Roe S, Harel R, Wikelski M, Getz WM: Using tri-axial acceleration data to identify behavioral modes of free-ranging animals: general concepts and tools illustrated for griffon vultures. J Exp Biol 2012, 215(Pt 6):986-996.

13. Fryxell JM, Hazell M, Börger L, Dalziel BD, Haydon DT, Morales JM, Mclntosh T, Rosatte RC: Multiple movement modes by large herbivores at multiple spatiotemporal scales. Proc Natl Acad Sci U S A 2008, 105:19114-19119.

14. Dalziel BD, Morales JM, Fryxell JM: Fitting probability distributions to animal movement trajectories: using artificial neural networks to link distance, resources, and memory. Am Nat 2008, 172:248-258.

15. Boettiger AN, Wittemyer G, Starfield R, Volrath F, Douglas-Hamilton I, Getz WM: Inferring ecological and behavioral drivers of African elephant movement using a linear filtering approach. Ecology 2011, 92:1648-1657.

16. Getz W, Saltz D: A framework for generating and analyzing movement paths on ecological landscapes. Proceedings of the National Academy of Sciences 2008, 105(49)19066-19071. doi:10.1073/pnas.0801732105.

17. Adams J, Flora S: Correlating seabird movements with ocean winds: linking satellite telemetry with ocean scatterometry. Mar Biol 2009, 157:915-929.

18. Shamoun-Baranes J, Bouten W, Camphuysen CJ, Baaij E: Riding the tide: intriguing observations of gulls resting at sea during breeding. IBIS: The International Journal of Avian Science 2011, 153:411-415.

19. Shamoun-Baranes J, Van Loon EE, Alon D, Alpert P, Yom-Tov $Y$, Leshem Y: Is there a connection between weather at departure sites, onset of migration and timing of soaring-bird autumn migration in Israel? Glob Ecol Biogeogr 2006, 15:541-552.

20. Shamoun-Baranes J, Leshem Y, Yom-Tov $Y$, Liechti O: Differential use of thermal convection by soaring birds over central Israel. Condor 2003, 105:208-218.

21. Shamoun-Baranes J, Baharad A, Alpert P, Berthold P, Yom-Tov Y, Dvir $Y$, Leshem $Y$ : The effect of wind, season and latitude on the migration speed of white storks Ciconia ciconia, along the eastern migration route. J Avian Biol 2003, 34:97-104.

22. Spaar R, Bruderer B: Soaring migration of Steppe Eagles Aquila nipalensis in Southern Israel: Flight behaviour under various wind and thermal conditions. J Avian Biol 1996, 27:289-301.

23. Klaassen M, Beekman JH, Kontiokorpi J, Mulder RJW, Nolet BA: Migrating swans profit from favourable changes in wind conditions at low altitude. J Ornithol 2004, 145:142-151.

24. Kemp MU, Shamoun-Baranes J, Van Loon EE, McLaren JD, Dokter AM, Bouten W: Quantifying flow-assistance and implications for movement research. J Theor Biol 2012, 308:56-67.

25. Katzner TE, Brandes D, Miller T, Lanzone M, Maisonneuve C, Tremblay JA, Mulvihill R, Merovich GT: Topography drives migratory flight altitude of golden eagles: implications for on-shore wind energy development. J Appl Ecol 2012, 49:1178-1186.

26. Kemp MU, van Loon E, Shamoun-Baranes J, Bouten W: RNCEP: global weather and climate data at your fingertips. Methods in Ecology and Evolution 2012, 3:65-70.

27. Dodge $S$, Weibel $R$, Lautenschütz A-K: Towards a taxonomy of movement patterns. Inf Vis 2008, 7:240-252.

28. Buchin M, Dodge S, Speckmann B: Context-Aware Similarity of Trajectories. Lecture Notes in Computer Science, Proceedings of the 7th International Conference GIScience 2012 2012, 7478:43-56.

29. Kranstauber B, Cameron A, Weinzerl R, Fountain T, Tilak S, Wikelski M, Kays $\mathrm{R}$ : The Movebank data model for animal tracking. Environ Model Software 2011, 26:834-835.

30. Wikelski M, Kays R: Movebank: archive, analysis and sharing of animal movement data. World Wide Web electronic publication. http://www. movebank.org, access in 2013.

31. Phillips SJ, Anderson RP, Schapire RE: Maximum entropy modeling of species geographic distributions. Ecol Model 2006, 190:231-259.

32. The Move R-package.; http://cran.r-project.org/web/packages/move/index. html http://computational-ecology.com/main-move.html.

33. Li Z, Han J, Ji M, Tang L, Yu Y, Ding B, Lee J-G, Kays R: MoveMine: Mining Moving Object Data for Discovery of Animal Movement Patterns. ACM Transactions on Intelligent Systems and Technology (ACM TIST) 2011, 2:37.

34. Hawkes LA, Balachandran S, Batbayar N, Butler PJ, Chua B, Douglas DC, Frappell PB, Milsom WK, Newman SH, Prosser DJ, Sathiyaselvam P, Scott GR, Takekawa JY, Wikelski M, Witt MJ, Yan B, Bishop CM: The paradox of extreme high-altitude migration in bar-headed geese Anser indicus. 
Proceedings Biological sciences / The Royal Society 2013, 280. doi:10.1098/rspb.2012.2114.

35. Battley PF, Warnock N, Tibbitts TL, Gill RE, Piersma T, Hassell CJ, Douglas DC, Mulcahy DM, Gartrell BD, Schuckard R, Melville DS, Riegen AC: Contrasting extreme long-distance migration patterns in bar-tailed godwits Limosa lapponica. J Avian Biol 2012, 43:21-32.

36. Safi K, Kranstauber B, Kays R, Weinzerl R, Griffin L, Cruz S, Takekawa J, Wikelski M, Bohrer G: Flying with the wind. Movement Ecology, in press.

37. Kummerow C, Barnes W, Kozu T, Shiue J, Simpson J: The Tropical Rainfall Measuring Mission (TRMM) Sensor Package. J Atmos Oceanic Tech 1998, 15:809-817.

38. Tucker C, Pinzon J, Brown M, Slayback D, Pak E, Mahoney R, Vermote E, El Saleous N: An extended AVHRR 8-km NDVI dataset compatible with MODIS and SPOT vegetation NDVI data. Int I Remote Sens 2005, 26:4485-4498.

39. Kanamitsu M, Ebisuzaki W, Woollen J, Yang S-K, Hnilo JJ, Fiorino M, Potter GL: NCEP-DOE AMIP-II Reanalysis (R-2). Bull Am Meteorol Soc 2002, 83:1631-1643.

40. Mesinger F, DiMego G, Kalnay E, Mitchell K, Shafran PC, Ebisuzaki W, Jović D, Woollen J, Rogers E, Berbery EH, Ek MB, Fan Y, Grumbine R, Higgins W, Li H, Lin Y, Manikin G, Parrish D, Shi W: North American Regional Reanalysis. Bull Am Meteorol Soc 2006, 87:343-360.

41. Dee DP, Uppala SM, Simmons AJ, Berrisford P, Poli P, Kobayashi S, Andrae U, Balmaseda MA, Balsamo G, Bauer P, Bechtold P, Beljaars ACM, Van de Berg L, Bidlot J, Bormann N, Delsol C, Dragani R, Fuentes M, Geer AJ, Haimberger L, Healy SB, Hersbach H, Hólm EV, Isaksen L, Kålllberg P, Köhler M, Matricardi M, McNally AP, Monge-Sanz BM, Morcrette JJ, et al: The ERA-Interim reanalysis: configuration and performance of the data assimilation system. Q J Roy Meteorol Soc 2011, 137:553-597.

42. Behrenfeld M, Falkowski PG: A consumer's guide to phytoplankton primary productivity models. Limnol Oceanogr 1997, 42:1479-1491.

43. Reuter HI, Nelson A, Jarvis A: An evaluation of void-filling interpolation methods for SRTM data. Int I Geogr Inf Sci 2007, 21:983-1008.

44. Jenness JS: Calculating landscape surface area from digital elevation models. Wildl Soc Bull 2004, 32:829-839.

45. Li J, Heap AD: A review of comparative studies of spatial interpolation methods in environmental sciences: Performance and impact factors. Ecological Informatics 2011, 6:228-241.

46. Lam NS-N: Spatial Interpolation Methods: A Review. Cartogr Geogr Inf SCi 1983, 10:22.

47. Anderson DJ, Huyvaert KP, Wood DR, Gillikin CL, Frost BJ, Mouritsen H: At-sea distribution of waved albatrosses and the Galápagos Marine Reserve. Biol Conserv 2003, 110:367-373.

48. Weimerskirch H, Guionnet T, Martin J, Shaffer SA, Costa DP: Fast and fuel efficient? Optimal use of wind by flying albatrosses. Proceedings Biological sciences, The Royal Society 2000, 267:1869-1874.

doi:10.1186/2051-3933-1-3

Cite this article as: Dodge et al.: The environmental-data automated track annotation (Env-DATA) system: linking animal tracks with environmental data. Movement Ecology 2013 1:3.

\section{Submit your next manuscript to BioMed Central and take full advantage of:}

- Convenient online submission

- Thorough peer review

- No space constraints or color figure charges

- Immediate publication on acceptance

- Inclusion in PubMed, CAS, Scopus and Google Scholar

- Research which is freely available for redistribution

Submit your manuscript at www.biomedcentral.com/submit 